\title{
An extrahippocampal projection from the dentate gyrus to the olfactory tubercle Heinz Künzle*
}

\author{
Address: Institute of Anatomy, Ludwig Maximilians-University, Pettenkoferstrasse 11, D-80336 Munich, Germany \\ Email: Heinz Künzle* - Heinz@kuenzle.de \\ * Corresponding author
}

Published: 3I May 2005

BMC Neuroscience 2005, 6:38 doi:10.1 186/147|-2202-6-38

This article is available from: http://www.biomedcentral.com/I47I-2202/6/38

(C) 2005 Künzle; licensee BioMed Central Ltd.

This is an Open Access article distributed under the terms of the Creative Commons Attribution License (http://creativecommons.org/licenses/by/2.0), which permits unrestricted use, distribution, and reproduction in any medium, provided the original work is properly cited.
Received: 20 January 2005

Accepted: 31 May 2005

\begin{abstract}
Background: The dentate gyrus is well known for its mossy fiber projection to the hippocampal field 3 (CA3) and its extensive associational and commissural connections. The dentate gyrus, on the other hand, has only few projections to the CAI and the subiculum, and none have clearly been shown to extrahippocampal target regions.

Results: Using anterograde and retrograde tracer techniques in the Madagascan lesser hedgehog tenrec (Afrosoricidae, Afrotheria) it was shown in this study that the dentate hilar region gave rise to a faint, but distinct, bilateral projection to the most rostromedial portion of the olfactory tubercle, particularly its molecular layer. Unlike the CAI and the subiculum the dentate gyrus did not project to the accumbens nucleus. A control injection into the medial septum-diagonal band complex also retrogradely labeled cells in the dentate hilus, but these neurons were found immediately adjacent to the heavily labeled CA3, while the tracer injections into the rostromedial tubercle did not reveal any labeling in CA3.

Conclusion: The dentate hilar neurons projecting to the olfactory tubercle cannot be considered displaced cells of CA3 but represent true dentato-tubercular projection neurons. This projection supplements the subiculo-tubercular projection. Both terminal fields overlap among one another as well as with the fiber terminations arising in the anteromedial frontal cortex. The rostromedial olfactory tubercle might represent a distinct ventral striatal target area worth investigating in studies of the parallel processing of cortico-limbic information in tenrec as well as in cat and monkey.
\end{abstract}

\section{Background}

The dentate gyrus (Dt) may be known best for its input from the entorhinal cortex and its mossy fiber projection to the CA3 [1-3]. In addition, the Dt has extensive associational and commissural connections [4-8] considered crucial for the generation of gamma frequency oscillations and learning (e.g. [9-11]). Most attention among the dentate interneurons may recently have received the cells in the hilus region (DtHi) due to their vulnerability to vari- ous injuries [12-14] as well as their remarkable structural, histochemical and electrophysiological diversity [15-20]. A few hilar neurons also project to the cornu ammonis (CA) and the subiculum (Sbi) $[15,21]$. Extrahippocampal projections from the dentate gyrus, however, are not known with the exception from some septal projecting neurons in the DtHi [22-25] usually considered displaced cells of CA3 $[1,21]$. 
Table I: Cases showing hippocampo-basal telencephalic projections with anterograde tracing techniques

\begin{tabular}{|c|c|c|c|c|}
\hline \multirow[t]{2}{*}{ Case } & \multirow[t]{2}{*}{ Injection site } & \multicolumn{3}{|c|}{ Terminal projections } \\
\hline & & $\mathbf{T u}$ & Acb & DgMS \\
\hline $\mathrm{EtOI}-36 \mathrm{~B}$ & $\mathrm{DtMo}>>\mathrm{DtGr}_{ \pm \mathrm{DtHi}}$ & - & - & - \\
\hline Et0I-2IB & $\mathrm{DtMo}>\mathrm{DtGr} r_{ \pm \mathrm{DtHi}}$ & ++ & - & \pm \\
\hline Et00-IIB & $\mathrm{Dt}>\mathrm{CA} 3$ & + & - & $+++b$ \\
\hline Et98-49W & $\mathrm{Dt}>\mathrm{CA} 3$ & + & - & $++c$ \\
\hline Et00-08B & Dt, CAI & + & - & $++a$ \\
\hline Et00-13W & $\mathrm{Dt}, \mathrm{CAl}<\mathrm{Sbi}$ & + & ++ & $+++c$ \\
\hline Et00-4IB & Sbi & ++ & ++ & $+++a$ \\
\hline
\end{tabular}

Letters $B$ and $W$ following the case numbers indicate the tracer injected, BDA and WGA-HRP respectively. The regions injected with tracer are written with large or small letters depending on their major or minor contribution to the projection pattern ( \pm indicates questionable involvement). The symbols -,,,, \pm++++++ (none, questionable, weak, moderate, strong) refer to the overall intensity and extent of the projections. The letters superscripted in column DgMS refer to additional labeling of isolated (a), few (b) and numerous (c) cell bodies.

Continuing our attempts to elucidate the hippocampal and parahippocampal circuits in mammals with a poorly differentiated brain [26-29] the present study in the lesser hedgehog tenrec (Echinops telfairi, Et) will demonstrate some true dentate hilar cells projecting to a circumscribed region in the olfactory tubercle. The projection may represent an additional parallel pathway transferring corticolimbic information to the ventral striatum [30-32].

\section{Results}

Axo-terminal labeling in the striatum following tracer injections into the dentate gyrus

Among the experiments with tracer injections into the hippocampus (Table 1) two cases were injected with biotinylated dextran amine (BDA) into the dentate area exclusively. These tracer injections mainly involved the dentate molecular layer (DtMo) but there was some tracer uptake by the granule cells as seen from the weak to moderate mossy fiber projection to CA3 (Fig. 1). The sparse (Et0136B, Fig. 1C) to moderate (Et01-21B, Fig. 1A) number of labeled cells in the dentate hilar region subjacent to the main injection site might be due to a retrogarde transport and/or a direct uptake of tracer substance. In Et00-11B and Et98-49W (Fig. 1B) all layers of Dt as well as the adjacent portions of CA3 were labeled directly with BDA and wheat germ agglutinin conjugated to horseradish peroxidase (WGA-HRP), respectively (the letters $\mathrm{B}$ and $\mathrm{W}$ following the case number indicate the tracer injected). The Dt and portions of CA1 were injected with BDA in Et0008B, while in the remaining experiments the injection involved the subiculum (Sbi) with (Et00-13W) or without (Et00-41B) an involvement of the Dt and CA1.

The latter two cases revealed the well-known hippocampo-striatal projection pattern to the nucleus accumbens (Acb) and the olfactory tubercle (Tu) [29]. No hippocampo-striatal projection, on the other hand, was found in Et01-36B (Table 1, Fig. 1G) injected with tracer almost exclusively into the DtMo. The remaining cases consistently showed some fiber labeling in the Tu (Fig. $1 \mathrm{E}, 1 \mathrm{~F}, 1 \mathrm{H})$ but did not reveal any projections to the Acb (Table 1; Fig. 1D). The labeling in Tu involved especially the molecular layer in the medial quarter of $\mathrm{Tu}$ at levels rostral to the insula magna. In all cases but Et01-21B the hippocampo-tubercular projection was represented on both sides with a slight ipsilateral predominance (Fig. $1 \mathrm{H}, 1 \mathrm{I}, 1 \mathrm{~J})$.

In Et01-21B the course of fibers towards Tu appeared to pass exclusively within the molecular layer of the hippocampal continuation ( $\mathrm{HCt}$; Fig. 1D; also note the difference to Fig. $1 \mathrm{G}$ of Et01-36B). In the other cases labeled fibers were seen in the HCt as well as the fornix. A fiber course across the fornix appeared most likely for the contralateral projection as far as the contralateral HCt was almost unlabeled and a fiber crossing was never observed for the HCt-fibers unlike the fornix fibers.

For the subsequent experiments carried out in order to identify more accurately the origin of the hippocampotubercular projections, it should be mentioned that similar to other reports [33] there were also hippocampal projections to the diagonal band-medial septum complex (DgMS). Evidence for these projections was obtained from the BDA experiments which revealed an extensive terminal-like fiber pattern across the DgMS, but only few, if any labeled perikarya unlike the WGA-HRP experiments (Table 1). 

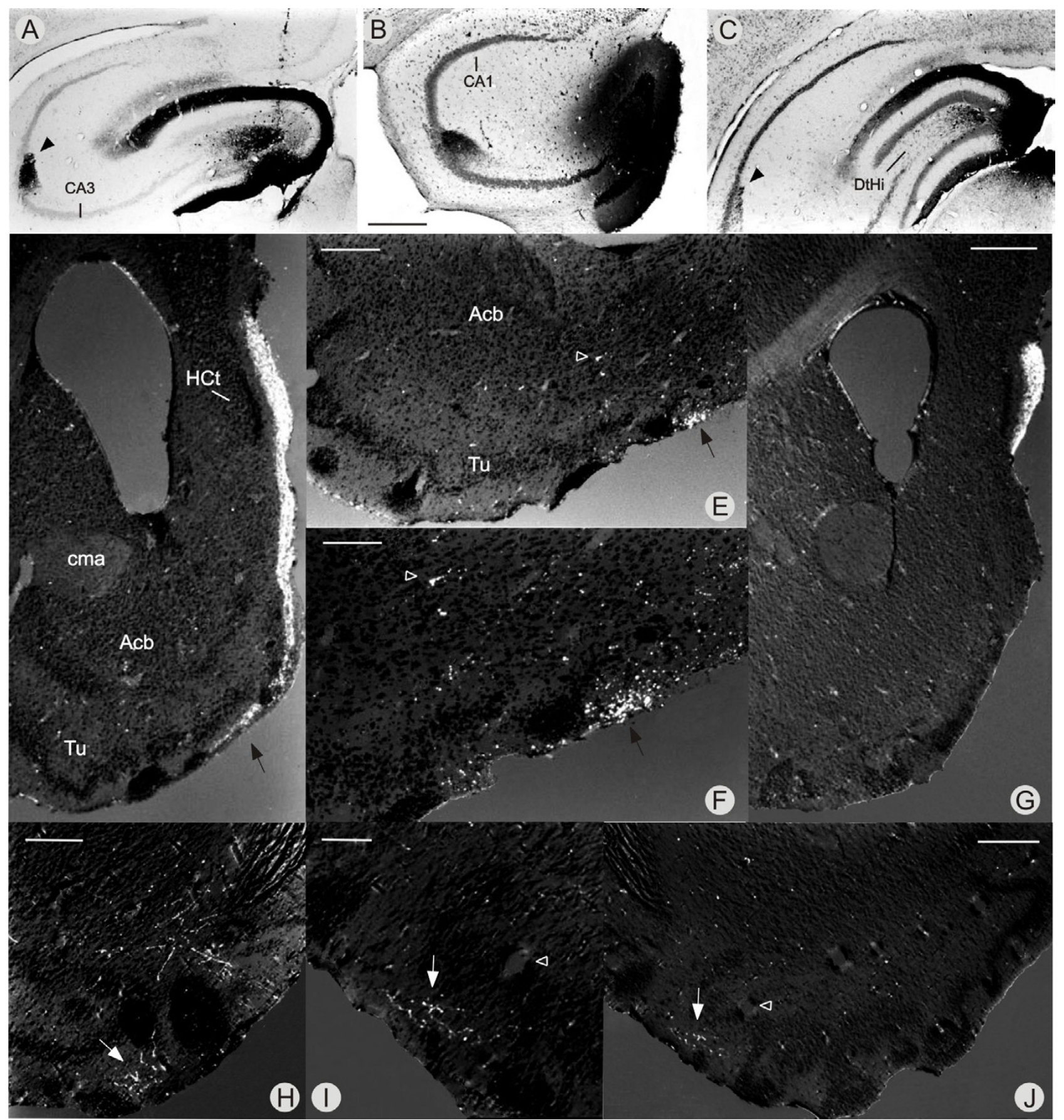

\section{Figure I}

Anterograde labeling in the olfactory tubercle following tracer injections into the dentate gyrus. Photomicrographs taken by transmitted and polarized light showing anterograde projections to the olfactory tubercle (D, E, F, H, I, J; arrows point to labeling) and/or the anterior hippocampal continuation $(D, G)$ following tracer injections into the dentate gyrus in EtOI-2IB (A, D), Et98-49W (B, E, F), EtOI-36B (C, G) and Et00-I IB (H - J). The molecular layer of Tu was labeled in all cases (D-H, ipsilateral side; I and J, contralateral side) but Et0I-36B (G) where the tracer injection scarcely involved the $\mathrm{DtHi}$ (note the low labeling density of the mossy fiber projection to CA3 in C [arrow head] as compared to $A$ ). The Acb (D, E) was not labeled following tracer injections into Dt unlike the cases injected with tracer into CAI / Sbi. All BDA cases also clearly labeled the $\mathrm{HCt}(\mathrm{D}, \mathrm{G})$ due to the retrograde-anterograde collateral transport of the tracer within the entorhino-hippocampal system described previously [28]. Open arrow heads in E, F and I, J respectively point to similar location. Scale bars in $B$ (also applying to $A$ and $C$ ) and $G$ (also applying to D) $0.5 \mathrm{~mm}$; in $E$ and J $=0.4 \mathrm{~mm}$, in $\mathrm{H}=0.3 \mathrm{~mm}$; in $F$ and $\mathrm{I}=0.2 \mathrm{~mm}$. 
Table 2: Cases showing hippocampo-basal telencephalic projections with retrograde tracing techniques

\begin{tabular}{|c|c|c|c|c|c|}
\hline \multirow[t]{2}{*}{ Case } & \multirow[t]{2}{*}{ Injection site } & \multicolumn{4}{|c|}{ Origin of projection } \\
\hline & & DtHi & CA3 & CAI & Sbi \\
\hline Et03-58W & TuM & + & - & - & \pm \\
\hline Et0I-47W & $\mathrm{TuM}_{+\mathrm{HCt}}{ }^{*}$ & + \pm & - & \pm & ++ \\
\hline Et02-63W & $\mathrm{Acb}_{+\mathrm{FrCx}}$ & - & - & ++ & +++ \\
\hline Et02-65W & $A c b$ & - & - & ++ & +++ \\
\hline Et00-08W & $\mathrm{SeV}$ & ++ & +++ & +++ & +++ \\
\hline
\end{tabular}

The areas injected with tracer and the density of labeled perikarya are judged as in Table I.

* The contamination of the anterior $\mathrm{HCt}$ by the tracer is restricted to the third layer not connected with the hippocampus [28]. FrCx, frontal cortex; SeV, ventral septum.

\section{Perikaryal labeling in the dentate gyrus following tracer injections into the striatum and septum}

There were two cases with WGA-HRP injections involving the rostromedial Tu including its molecular layer (Table 2 ). The tracer injection in Et03-58W showed a relatively circumscribed injection site (Fig. 3A); a direct labeling of the DgMS, however, could not be excluded. In Et01-47W there was some loss of tracer along the electrode tract leading to a contamination of the third layer of the HCt. A control injection into the ventral septum including the DgMS (Fig. 10L in [26]) was available too as well as two tracer injections involving the Acb (Table 2; Fig. 2A).

Consistent with previous studies in subprimate species [34-38] the tracer injections into the Acb led to retrograde labeling of exclusively the Sbi and CA1 (Fig. 2B; regarding the involvement of CA3 in monkey see ref.[39]). The septal injection, in addition, labeled numerous neurons in CA3 (Fig. 2C, 2D) as well as a substantial number of cells in the DtHi adjacent to the heavily labeled CA3, particularly at caudal levels (Fig. 2D, 2E). In the cases injected with tracer into the Tu labeled cells were found in the HCt (Fig. 3B, 3C), the Sbi (Fig. 3F) and the DtHi (Figs. 3D,3E,3F,3G,3H). These cases, however, consistently failed to show any retrograde labeling in the CA3 (or the dentate granule cells layer). In Et03-58W the labeled neurons in the DtHi were restricted to its rostral third, while in Et01-47W they involved rostral as well as caudal portions of the hilus. The latter case also showed a very few labeled cells on the contralateral side. A particular distribution of the labeled cells within the DtHi was not obvious, and their poor dendritic labeling did not allow a further characterization of the cells.

\section{Discussion}

Unlike the dentate projection to the HCt the projection to the olfactory tubercle cannot be explained by a retrograde- anterograde collateral transport of tracer [28]. Tubercular terminations are not seen in the case with a BDA injection largely confined to the dentate molecular layer (Fig. $1 \mathrm{C}, 1 \mathrm{G})$, and tubercular projections are noted in the cases with dentate injections of WGA-HRP (Fig. 1B,1E,1F), a tracer substance not known to be transported in a retrograde-anterograde collateral fashion [40]. Moreover, the dentate-hilar neurons are also filled by the retrograde axonal flow from the tracer deposits in the Tu.

The projection to the olfactory tubercle differs from previously reported extrahippocampal projections from the dentate area as far as its cells of origin are confined to the DtHi while the septal $[22,23,41]$ and hypothalamic [42] projections arise predominantly from the CA and the Sbi, only sparsely from the DtHi. Unlike the latter cells, therefore, the dentato-tubercular neurons can not be considered displaced cells of CA3. We have not characterized yet the particular morphology and histochemistry of these neurons [16,26,43-45] and do not know whether their projections are distinct ones or arise as collaterals [46-49]. Nevertheless, it is a projection which involves a circumscribed region in the olfactory tubercle and avoids the nucleus accumbens, the main striatal target area of the hippocampus [34,35,39].

These findings are in line with previous suggestions considering the medial Tu as a separate striopallidal subdivision [50-53] and fit with the concept of the parallel processing of cortico-striatal information [30,31,54-56]. The question remains as to why a dentato-tubercular projection has not been demonstrated so far in other species. The projection may be unique to tenrecs or mammals with little differentiated brain but its apparent absence in other mammals may as well be explained by the low strength of its projection and/or its circumscribed field of termination. Such a projection may easily be overlooked 


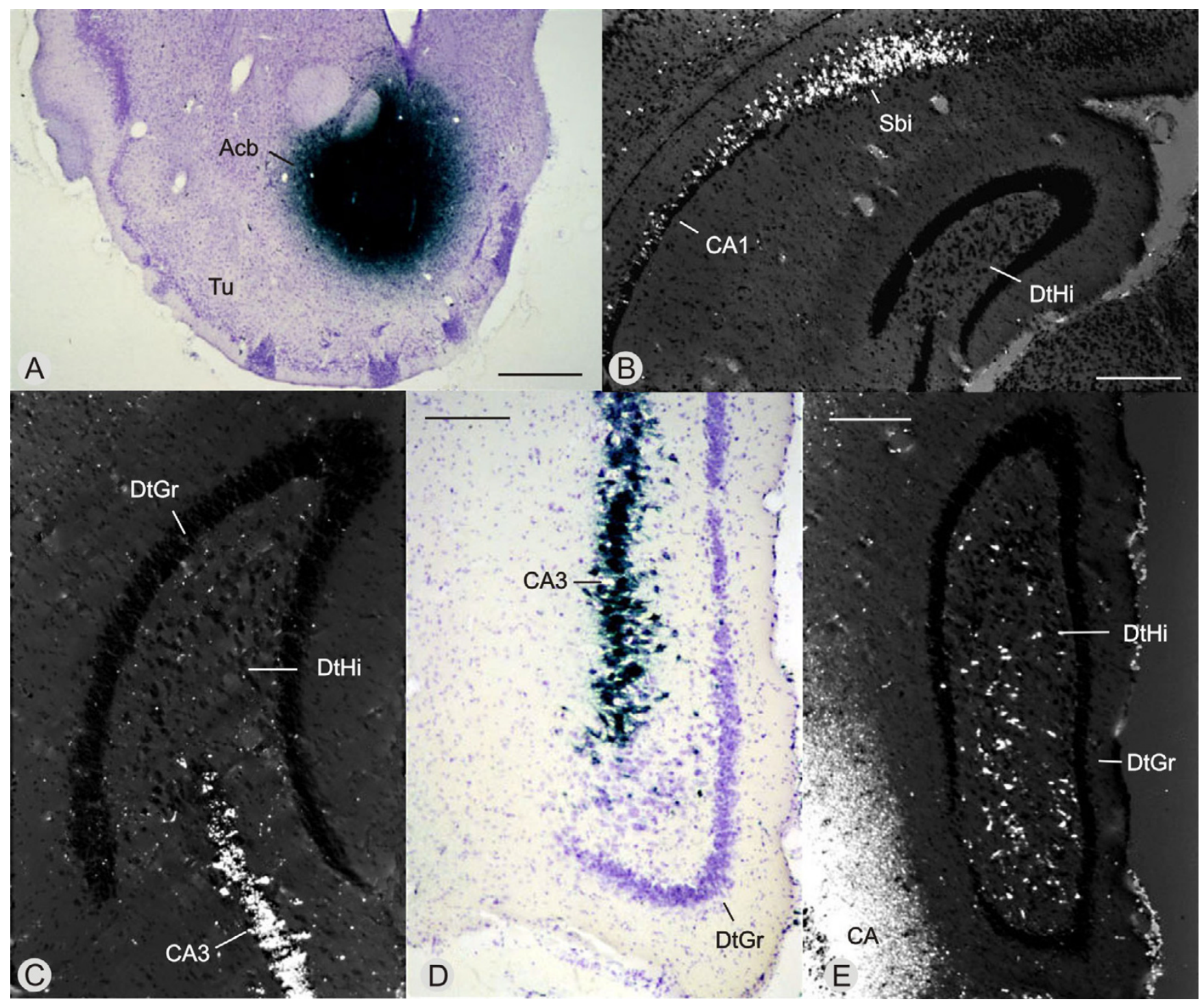

Figure 2

Retrograde labeling in the hippocampus following tracer injections into nucleus accumbens and septum. Following WGA-HRP injection into the $A c b(A)$ in Et02-65W there were numerous retrogradely labeled cells in Sbi and CAI (B), but none in CA3 and Dt (B). The tracer injection into the septum of Et00-08W (see Fig. I0L in [26]) also labeled heavily the CA3 (C-E) as well as some cells in the adjacent DtHi (D, E), particularly at caudal levels (section D is taken $960 \mu \mathrm{m}$ caudal to $\mathrm{C}$ and $160 \mu \mathrm{m}$ rostral to $E$ ). Scale bars $=0.8 \mathrm{~mm}$ in $A, 0.4 \mathrm{~mm}$ in $B, 0.3 \mathrm{~mm}$ in $E$ and $0.2 \mathrm{~mm}$ in $D$ (also applies to C).

in anterograde tracer studies, especially in species with a large brain. Retrograde tracer studies, on the other hand, have only been done in the rat and the hamster $[37,50,57,58]$ and it is questionable, whether their small circumscribed dentato-tubercular target area, if present, has been injected with tracer. Rodent species, in addition, are not representative for studying the hippocampo-tubercular projections. In the rat, the Tu receives considerably less hippocampal afferents from the CA1/Sbi fields [35] than in the tenrec [29], cat [34] and monkey [39]. Similarly, the relative strength of the entorhinal projections to the $\mathrm{Tu}$ as compared to the Acb is much less in rodents $[36,59,60]$ than in non-rodent species $[29,39,61]$. It may also be noted that the hippocampal continuation, the only other striatal input region projecting exclusively to the tenrec's rostromedial Tu [28], is poorly represented in the rat compared to other mammals [62]. One may speculate that the dentato-tubercular neurons in the DtHi rep- 


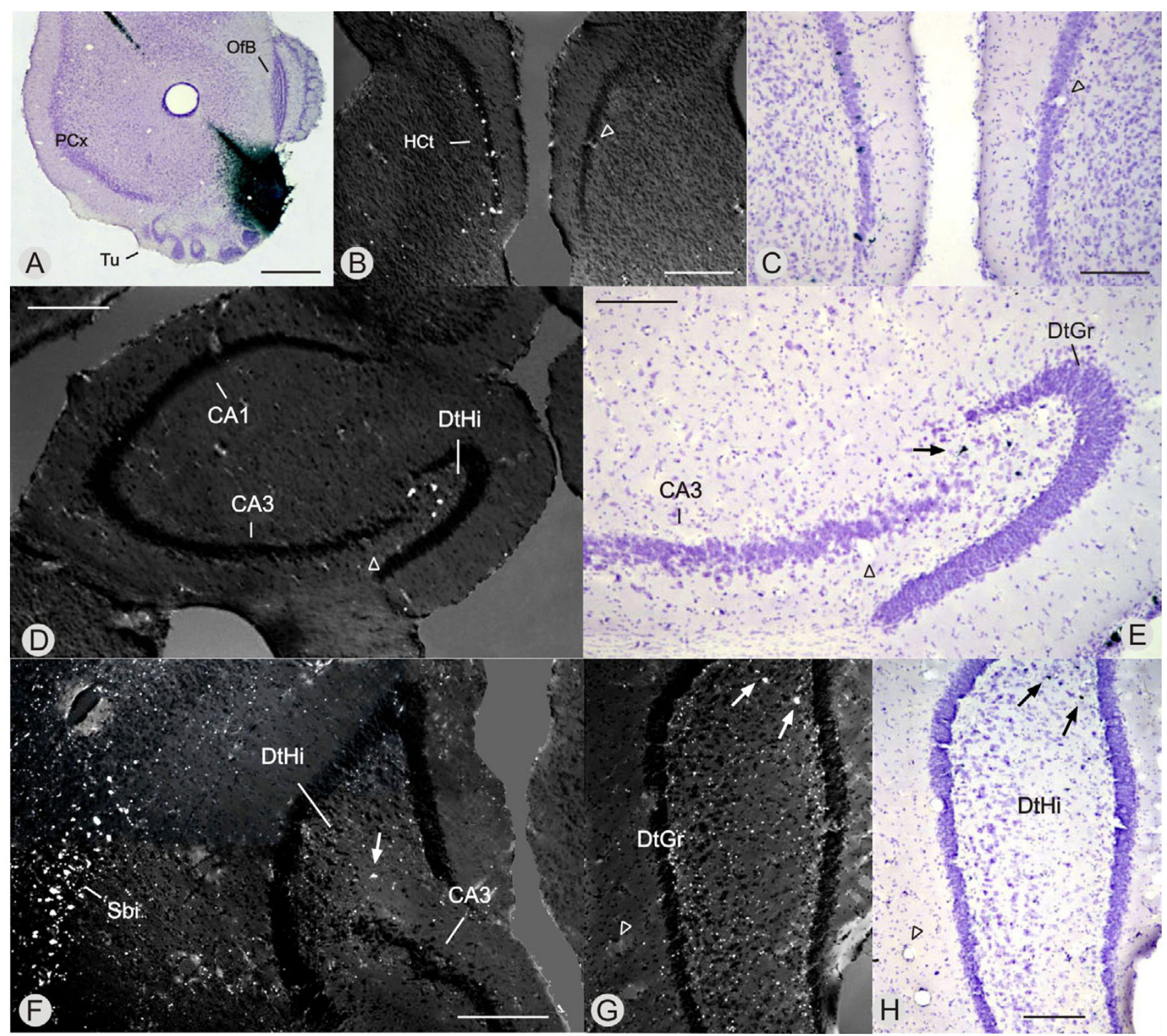

Figure 3

Retrograde labeling in DtHi and HCt following tracer injections into the olfactory tubercle. Tracer injections into the rostromedial Tu (A) consistently labeled a few dentate hilar neurons (D-H; arrows point to labeled cells), but failed to label the CA3 (D-F). A-E are from Et03-58W, F-H from Et0 I-47W. Some labeled neurons are also noted in the ipsilateral, anterior $\mathrm{HCt}(\mathrm{B}, \mathrm{C})$ confirming previous anterograde data [28]. Remarkably, both the HCt and the DtHi project to the rostromedial $\mathrm{Tu}$, but not to the Acb. Arrow heads point to similar location. OfB, olfactory bulb; PCx, paleocortex. Scale bars $=0.8 \mathrm{~mm}$ in $\mathrm{A}$, $0.4 \mathrm{~mm}$ in $B$ and $D, 0.3 \mathrm{~mm}$ in $F, 0.2 \mathrm{~mm}$ in $C$, $E$ and $H$ (as $G$ ).

resent an extension of the HCt into the dentate gyrus and are only present in species showing a well differentiated HCt as e.g. in tenrecs and primates [62].

Unfortunately we still know little about the precise connectivity of the circumscribed dentato-tubercular target area. It receives few if any direct projections from the olfactory bulb (personal reinvestigation of the material published previously [63]) but gets a distinct input from the anteromedial frontal cortex [29]. The dentato-tubercular target area is likely to be part of a cortico-basal gangliathalamo-cortical loop involving the mediodorsal nucleus 
[64-67] and the prefrontal cortex, at least in subprimate species (rat: [68-70]; cat: [71]; monkey: [72-74]). Notably, while the prefrontal and hippocampal afferents to the Acb terminate in a predominantly non-overlapping fashion $[29,32,75]$, the cortico-striatal fibers appear to overlap considerably with the hippocampal afferents in the Tu.

\section{Conclusion}

The present data show for the first time a projection from the dentate gyrus to the rostromedial olfactory tubercle. Its cells of orgin, located in the dentate hilus, cannot be considered displaced neurons of CA3 but represent true dentato-tubercular projection neurons. The projection is assumed to be present in other mammals, too. In the tenrec the dentato-tubercular projection overlaps with the subiculo-tubercular projection and the fiber terminations arising in the anteromedial frontal cortex. The circumscribed ventral striatal target area appears worth investigating in studies of the parallel processing of corticolimbic information in tenrec as well as in cat and monkey.

\section{Methods}

\section{Animals}

The lesser hedgehog tenrec (Echinops telfairi, Et) is a member of the tenrecomorpha classically considered an insectivoran suborder [76] but actually grouped within the superorder Afrotheria (order Afrosoricida e.g. $[77,78]$ ). The animals were obtained from our breeding colony [79] built up to investigate their little differentiated forebrain and get an insight into the evolution of the mammalian brain $[80,81]$.

\section{Tracer injections}

Eleven tenrecs weighing between 80 and 140 gm were anesthetized with tribromoethanol $(1.0 \mathrm{ml} / 100 \mathrm{gm}$, i.p. $)$ and injected with tracer into the hippocampus $(\mathrm{n}=7)$, the ventral striatum $(n=4)$ and the septum $(n=1)$ following the German laws on protection of animals (one animal received two injections at different locations). Wheat germ agglutinin conjugated to horseradish peroxidase (WGA-HRP; Sigma; $\mathrm{n}=7$ ) and biotinylated dextran amine (BDA; Sigma; $n=5$ ) were used as tracer substances. Most cases have been described previously with regard to other connections $[26,28,82]$. The additional tracer injections (Et01-47W, Et03-58W) were done in the same fashion: The WGA-HRP $(1.5-8 \mathrm{nl}$ of a $2-5 \%$ solution in distilled water) was pressure injected through a glass micropipette (tip diameter 8-15 $\mu \mathrm{m}$ ) attached to a Hamilton syringe driven by a micromanipulator. The BDA was injected iontophoretically ( $10 \%$ in $0.01 \mathrm{M}$ phosphate buffer, $\mathrm{pH}$ 7.25; current of 2-5 $\mu \mathrm{A}$ for 5-10 min). After a survival time of 2-7 days the animals were reanesthetized and perfused transcardially with saline. The fixation consisted of a phosphate-buffered solution containing $1 \%$ parafor- maldehyde and $2.5 \%$ glutaraldehyde, followed by a phosphate-buffered solution containing $15 \%$ sucrose.

\section{Tissue processing}

The brains were soaked overnight in a 30\% phosphatebuffered sucrose solution, embedded in an albumin-gelatine mixture and cut on a freezing microtome at $40 \mu \mathrm{m}$ in the frontal plane. The WGA-HRP staining was usually done on two out of four sections according to the standard tetramethylbenzidine technique [83] and a modified tungstate-stabilized tetramethylbenzidine technique [84]. Following a pretreatment in mercaptoethanol ( $2 \%$ in 0.05 $\mathrm{M}$ PBS at $37^{\circ}$ for 5-15 min in order to suppress a staining of WGA-HRP) the BDA was visualized by incubating the sections in extravidin-peroxidase and developing the reaction product with nickel-enhanced diaminobenzidine and tungstate-stabilized tetramethylbenzidine (modified according to [84]) in an alternating fashion. The mounted sections were counterstained with neutral red (following treatment with diaminobenzidine and tetramethylbenzidine) and cresyl violet (following use of tungstate-stabilized tetramethylbenzidine). The tungstate-stabilized tetramethylbenzidine proved quite useful for visualizing faint projections but might result in large cristalline artefacts, particularly after overnight incubation.

\section{Data analysis}

Bright-field illumination and polarized light were used for the analysis. Images were captured on an Ilford 50 negative film or a Fujichrome 64T positive film (using a Zeiss axiophot microscope), scanned (Nikon Coolscan 5000) and transported into Adobe Photoshop (v. 7.0) and Corel Draw (v. 11.0). The sharpness, contrast and brightness were adjusted to reflect the appearance of the labeling seen through the microscope. For the sake of clarity the most disturbing crystalline artefacts were removed, particularly in darkfield images. In some darkfield micrographs the light reflecting embedding medium was also removed. Furthermore to facilitate the analysis all micrographs are shown with the injection site on the left.

\section{List of Abbreviations}

Acb - nucleus accumbens

BDA - biotinylated dextran amine

CA1/3 - subfields of cornu ammonis

cma - commissura anterior

DgMS - diagonal band-medial septum complex

Dt - dentate area

DtGr - dentate granule cell layer 
DtHi - dentate hilar region

DtMo - dentate molecular layer

Et - Echinops telfairi

HCt - hippocampal continuation

Sbi - subiculum

$\mathrm{Tu}$ - olfactory tubercle

WGA-HRP - wheat germ agglutinin conjugated to horseradish peroxidase

\section{Acknowledgements}

The excellent technical assistance of Angelika Antonius, Amela Klaus, Antonja Nekic and Sigi Schaller is gratefully acknowledged. The work was supported by the Deutsche Forschungsgemeinschaft, grant Ku 624/3-2.

\section{References}

I. Amaral DG, Witter MP: Hippocampal formation. In The Rat Nervous System 2nd edition. Edited by: Paxinos G. San Diego, New York, Boston, London, Sydney, Tokyo, Toronto: Academic Press; 1995:443-493.

2. Patton $\mathrm{PE}, \mathrm{McNaughton} \mathrm{B}$ : Connection matrix of the hippocampal formation. I. The dentate gyrus. Hippocampus 1995 5:245-286.

3. Henze DA, Urban NN, Barrioneuvo G: The multifarious hippocampal mossy fiber pathway: A review. Neuroscience 2000, 98:407-427.

4. Laurberg S, Sorensen KE: Associational and commissural collaterals of neurons in the hippocampal formation (hilus fasciae dentatae and subfield CA3). Brain Res 198I, 2 I 2:287-300.

5. Han ZS, Buhl EH, Lörinczi Z, Somogyi P: A high degree of spatial selectivity in the axonal and dendritic domains of physiologically identified local-circuit neurons in the dentate gyrus of the rat hippocampus. Europ J Neurosci 1993, 5:395-4I0.

6. Deller T, Nitsch R, Frotscher M: Phaseolus vulgaris - Leucoagglutinin tracing of commissural fibers to the rat dentate gyrus: Evidence for a previously unknown commissural projection to the outer molecular layer. J Comp Neurol 1995, 352:55-68.

7. Buckmaster PS, Wenzel HJ, Kunkel DD, Schwartzkroin PA: Axon arbors and synaptic connections of hippocampal mossy cells in the rat in vivo. J Comp Neurol 1996, 366:270-292.

8. Zappone CA, Sloviter RS: Commissurally projecting inhibitory interneurons of the rat hippocampal dentate gyrus: A colocalization study of neuronal markers and the retrograde tracer Fluoro-Gold. I Comp Neurol 200I, 44 I:324-344.

9. Bartos M, Vida I, Frotscher M, Meyer A, Monyer H, Geiger JRP, Jonas $P$ : Fast synaptic inhibition promotes synchronized gamma oscillations in hippocampal interneuron networks. PNAS 2002, 99: I 3222-13227.

10. Fuchs EC, Doheny H, Faulkner H, Caputi A, Traub RD, Bibbig A, Kopell N, Whittington MA, Monyer $\mathrm{H}$ : Genetically altered AMPA-type glutamate receptor kinetics in interneurons disrupt long-range synchrony of gamma oscillation. PNAS 200I, 98:357I-3576.

II. Ross ST, Soltesz I: Long-term plasticity in interneurons of the dentate gyrus. PNAS 2001, 98:8874-8879.

12. Santhakumar V, Bender R, Frotscher M, Ross ST, Hollrigel GS, Toth Z, Soltesz I: Granule cell hyperexcitability in the early posttraumatic rat dentate gyrus: the 'irritable mossy cell' hypothesis. J Physiol 2000, 524: I I7-I34.

13. Scharfman HE, Smith KL, Goodman JH, Sollas AL: Survival of dentate hilar mossy cells after pilocarpine-induced seizures and their synchronized burst discharges with area CA3 pyramidal cells. Neuroscience 2001, 1 04:74|-799.
14. Zappone CA, Sloviter RS: Translamellar disinhibition in the rat hippocampal dentate gyrus after seizure-induced degeneration of vulnerable hilar neurons. J Neurosci 2004, 24:864-853.

15. Buckmaster PS, Schwartzkroin PA: Physiological and morphological heterogeneity of dentate gyrus-hilus interneurons in the gerbil hippocampus in vivo. Europ J Neurosci 1995, 7:|393-|402.

16. Freund TF, Buzsaki G: Interneurons of the hippocampus. Hippocampus 1996, 6:347-470.

17. Mott DD, Turner DA, Okazaki MM, Lewis DV: Interneurons of the dentate-hilus of the rat dentate gyrus: Morphological and electrophysiological heterogeneity. I Neurosci 1997, I 7:3990-4005.

18. Forti M, Michelson HB: Synaptic connectivity of distinct hilar interneuron subpopulations. I Neurophysiol 1998, 79:3229-3237.

19. Acsády L, Katona I, Martinez-Guijarro FJ, Buzsáki G, Freund TF: Unusual target selectivity of perisomatic inhibitory cells in the hilar region of the rat hippocampus. I Neurosci 2000 , 20:6907-6919.

20. Rácz B, Halasy K: Kappa opioid receptor is expressed by somatostatin- and neuropeptide $Y$-containing interneurons in the rat hippocampus. Brain Res 2002, 93 I:50-55.

21. Sik A, Penttonen M, Buzsáki G: Interneurons in the hippocampal dentate gyrus: an in vivo intracellular study. Europ / Neurosci 1997, 9:573-588.

22. Chronister RB, DeFrance JF: Organization of projection neurons of the hippocampus. Exp Neurol 1979, 66:509-523.

23. Alonso A, Köhler C: Evidence for separate projections of hippocampal pyramidal and non-pyramidal neurons to different parts of the septum in the rat brain. Neurosci Lett 1982 , 3 I :209-2 I 4 .

24. Jinno S, Kosaka T: Immunocytochemical characterization of hippocamposeptal projecting GABAergic nonprincipal neurons in the mouse brain: a retrograde labeling study. Brain Res 2002, 945:219-23।.

25. Gulyás Al, Katona I, Freund TF: Interneurons are the local targets of hippocampal inhibitory cells which project to the medial septum. Europ J Neurosci 2003, I 7:|86|-|872.

26. Künzle H, Radtke-Schuller S: Hippocampal fields in the hedgehog tenrec. Their architecture and major intrinsic connections. Neurosci Res 2001, 41:267-291.

27. Künzle H: Neocortical connections with perihippocampal and periamygdalar regions in the hedgehog tenrec. Anat Embryol 2003, 207:389-407.

28. Künzle $\mathrm{H}$ : The hippocampal continuation (indusium griseum). Its connectivity in the hedgehog tenrec and its status within the hippocampal formation of higher vertebrates. Anat Embryol 2004, 208:183-213.

29. Künzle H: The striatum in the hedgehog tenrec: Histochemical organization and cortical afferents. Brain Res 2005, 1034:90-I I3.

30. Alexander GE, Crutcher MD, Delong MR: Basal ganglia-thalamocortical circuits - Parallel substrates for motor, oculomotor, 'prefrontal' and 'limbic' functions. Progr Brain Res 1990 , 85: $119-146$

31. Groenewegen HJ, Galis-de Graaf Y, Smeets WJAJ: Integration and segregation of limbic cortico-striatal loops at the thalamic level: an experimental tracing study in rats. J Chem Neuroanat 1999, 16:167-185.

32. Thierry AM, Gioanni Y, Degenetais E, Glowinski J: Hippocampoprefrontal cortex pathway: Anatomical and electrophysiological characteristics. Hippocampus 2000, 10:4 I I-4I9.

33. Toth K, Borhegyi Z, Freund TF: Postsynaptic targets of GABAergic hippocampal neurons in the medial septum-diagonal band of Broca complex. I Neurosci 1993, 13:3712-3724.

34. Groenewegen HJ, Room P, Witter MP, Lohman AHM: Cortical afferents of the nucleus accumbens in the cat, studied with anterograde and retrograde transport techniques. Neuroscience 1982, 7:977-995.

35. Groenewegen $H$ J, van der Zee $\mathrm{V}$, te Kortschot A, Witter MP: Organization of the projection from the subiculum to the ventral striatum in the rat. A study using anterograde transport of Phaseolus vulgaris leucoagglutinin. Neuroscience 1987, 23:103-120.

36. Phillipson OT, Griffiths AC: The topographic order of inputs to nucleus accumbens in the rat. Neuroscience 1985, 16:275-296. 
37. McGeorge AJ, Faull RLM: The organization of the projection from the cerebral cortex to the striatum in the rat. Neuroscience 1989, 29:503-539.

38. Brog JS, Salyapongse A, Deutch AY, Zahm DS: The patterns of afferent innervation of the core and shell in the accumbens part of the rat ventral striatum - immunohistochemica detection of retrogradely transported fluoro-gold,. J Comp Neurol 1993, 338:255-278.

39. Friedman DP, Aggleton JP, Saunders RC: Comparison of hippocampal, amygdala, and perirhinal projections to the nucleus accumbens: Combined anterograde and retrograde tracing study in the macaque brain. I Comp Neurol 2002, 450:345-365.

40. Chen S, Aston-Jones G: Axonal collateral-collateral transport of tract tracers in brain neurons: false anterograde labelling and useful tool. Neuroscience 1998, 82:1।5I-II63.

4I. Schwerdtfeger WK, Buhl E: Various types of non-pyramidal hippocampal neurons project to the septum and contralateral hippocampus. Brain Res 1986, 386: |46-I54.

42. Ino T, Itoh K, Kamiya H, Shigemoto R, Akiguchi I, Mizuno N: Direct projections of non-pyramidal neurons of ammon's horn in the supramammillary region in the cat. Brain Res 1988 460: $173-177$.

43. Katona I, Acsády L, Freund TF: Postsynaptic targets of somatostatin-immunoreactive interneurons in the rat hippocampus. Neuroscience 1999, 88:37-55.

44. Einheber S, Pierce JP, Chow D, Znamensky V, Schnapp LM, Milner TA Dentate hilar mossy cells and somatostatin-containing neurons are immunoreactive for the $\alpha 8$ integrin subunit: characterization in normal and kainic acid-treated rats. Neuroscience 200I, I 05:619-638.

45. Jinno S, Kosaka T: Heterogeneous expression of the cholecystokinin-like immunoreactivity in the mouse hippocampus, with special reference to the dorsoventral difference. Neuroscience 2003, I 22:869-884.

46. Swanson LW, Sawchenko PE, Cowan WM: Evidence that the commissural, associational and septal projections of the regio inferior of the hippocampus arise from the same neurons. Brain Res 1980, 197:207-212.

47. Ishizuka N, Weber J, Amaral DG: Organization of intrahippocampal projections originating from CA3 pyramidal cells in the rat. J Comp Neurol 1990, 295:580-623.

48. Verwer RWH, Meijer RJ, Vanuum HFM, Witter MP: Collateral projections from the rat-hippocampal formation to the latera and medial prefrontal cortex. Hippocampus 1997, 7:397-402.

49. Chiba T: Collateral projection from the amygdalo-hippocam pal transition area and CAI to the hypothalamus and medial prefrontal cortex in the rat. Neurosci Res 2000, 38:373-383.

50. Záborszky L, Alheid GF, Beinfeld MC, Eiden LE, Heimer L, Palkovits $M$ : Cholecystokinin innervation of the ventral striatum: $A$ morphological and radioimmunological study. Neuroscience 1985, I 4:427-453.

51. Cools AR: Mesolimbic dopamine and its control of locomotor activity in rats: differences in pharmacology and light/dark periodicity between the olfactory tubercle and the nucleus accumbens. Psychopharmacol 1986, 88:45।-459.

52. Ikemoto S: Ventral striatal anatomy of locomotor activity induced by cocaine, D-amphetamine, dopamine and DI/D2 agonists. Neuroscience 2002, I I 3:939-955.

53. Zhou L, Furuta T, Kaneko T: Chemical organization of projection neurons in the rat accumbens nucleus and olfactory tubercle,. Neuroscience 2003, I 20:783-798.

54. Zahm DS: An integrative neuroanatomical perspective on some subcortical substrates of adaptive responding with emphasis on the nucleus accumbens. Neurosci Biobehav Rev 2000, 24:85-105.

55. Takada M, Tokuno H, Hamada I, Inase M, Ito $Y$, Imanishi M, Hasegawa $\mathrm{N}$, Akazawa T, Hatanaka N, Nambu A: Organization of inputs from cingulate motor areas to basal ganglia in macaque monkey. Eur J Neurosci 200 I, I4:1633-1650.

56. Christakou A, Robbins TW, Everitt B): Prefrontal cortical-ventral striatal interactions involved in affective modulation of attentional performance: Implications for corticostriatal circuit function. J Neurosci 2004, 24:773-780.

57. Newman R, Winans SS: An experimental study of the ventral striatum of the golden hamster. II. Neuronal connections of the olfactory tubercle. J Comp Neurol 1980, 191:193-212.
58. Totterdell S, Hayes L: Non-pyramidal hippocampal projection neurons: a light and electron microscopic study. J Neurocytol 1987, 16:477-485

59. Sorensen KE: Projections of the entorhinal area to the striatum, nucleus accumbens and cerebral cortex in the guinea pig. J Comp Neurol 1985, 238:308-322.

60. Totterdell S, Meredith GE: Topographical organization of projections from the entorhinal cortex to the striatum of the rat. Neuroscience 1997, 78:715-729.

6I. Witter MP, Groenewegen HJ: Connections of the parahippocampal cortex in the cat. IV. Subcortical efferents. J Comp Neurol 1986, 252:51-77.

62. Stephan H: Allocortex . In Handbuch der mikr Anatomie des Menschen Volume 4. Issue 9 Teil, Springer, Berlin, Heidelberg, New York, London, Paris, Tokyo; 1975.

63. Künzle $H$, Radtke-Schuller S: Basal telencephalic regions connected with the olfactory bulb in the Madagascan hedgehog tenrec. I Comp Neurol 2000, 423:706-726.

64. Velayos JL, Reinoso-Suarez F: Prosencephalic afferents to the mediodorsal thalamic nucleus. I Comp Neurol 1985 , 242: $|6|-|8|$

65. Russchen FT, Amaral DG, Price JL: The afferent input to the magnocellular division of the mediodorsal thalamic nucleus in the monkey, Macaca fascicularis. J Comp Neurol 1987 , 256: $175-210$.

66. Zahm DS, Heimer L: The ventral striatopallidothalamic projection. III. Striatal cells of the olfactory tubercle establish direct synaptic contact with ventral pallidal cells projecting to the mediodorsal thalamus. Brain Res 1987, 404:327-331.

67. Groenewegen $\mathrm{HJ}$ : Organization of the afferent connections of the mediodorsal thalamic nucleus in the rat, related to the mediodorsal-prefrontal topography. Neuroscience 1988, 24:379-432

68. Beckstead RM: An autoradiographic examination of corticocortical and subcortical projections of the mediodorsal-projection (prefrontal) cortex in the rat. J Comp Neurol 1979 , I 84:43-62.

69. Sesack SR, Deutch AY, Roth RH, Bunney BS: Topographical organization of the efferent projections of the medial prefrontal cortex in the rat: An anterograde tract-tracing study with Phaseolus vulgaris leucoagglutinin. J Comp Neurol 1989 , 290:213-242.

70. Berendse HW, Galis-de Graaf Y, Groenewegen HJ: Topographical organization and relationship with ventral striatal compartments of prefrontal corticostriatal projections in the rat. Comp Neurol 1992, 3 16:3 |4-347.

7I. Room P, Russchen FT, Groenewegen HJ, Lohman AHM: Efferent connections of the prelimbic (area 32) and the infralimbic (area 25) cortices: An anterograde tracing study in the cat. J Comp Neurol 1985, 242:40-55.

72. Haber SN, Kunishio K, Mizobuchi M, Lynd-Balta E: The orbital and medial prefrontal circuit through the primate basal ganglia. I Neurosci 1995, I 5:485|-4867.

73. Ferry AT, Ongur D, An X, Price J: Prefrontal cortical projections to the striatum in macaque monkeys: Evidence for an organization related to prefrontal networks. J Comp Neurol 2000, 425:447-470.

74. Chiba T, Kayahara T, Nakanoh K: Efferent projections of infralimbic and prelimbic areas of the medial prefrontal cortex in the Japanese monkey, Macaca fuscata. Brain Res 2001, 888:83- 101 .

75. French SJ, Totterdell S: Hippocampal and prefrontal cortical inputs monosynaptically converge with individual projection neurons of the nucleus accumbens. I Comp Neurol 2002 446: $|5|-\mid 65$

76. Eisenberg JF, Gould E: The tenrecs: A study in mammalian behavior and evolution. Smithson Contrib Zool I 970, 27: I- I 37.

77. Nikaido $M$, Cao $Y$, Okada N, Hasegawa $M$ : The phylogenetic relationships of insectivores with special reference to the lesser hedgehog tenrec as inferred from the complete sequence of their mitochondrial genome. Genes Genet Syst 2003, 78: I 07- I 12.

78. Douady CJ, Scally M, Springer MS, Stanhope MJ: "Lipotyphlan" phylogeny based on the growth hormone receptor gene: a reanalysis. Mol Phyl Evol 2004, 30:778-788. 
79. Künzle $\mathrm{H}$ : Care and breeding of the Madagascan hedgehog tenrec, Echinops telfairi, under laboratory conditions. Der Tierschutzbeauftragte 1998, 7:5-12. II3-115

80. Krubitzer $\mathrm{L}$, Künzle $\mathrm{H}$, Kaas J: Organization of sensory cortex in a Madagascan insectivore, the tenrec (Echinops telfairi). J Comp Neurol 1997, 379:399-4I4.

8I. Kaas $\mathrm{JH}$ : Evolution of somatosensory and motor cortex in primates. Anat Rec 2004, 28 I A: I I 48-I I 56.

82. Künzle H: Distribution of perihippocampo-hippocampal projection neurons in the lesser hedgehog tenrec. Neurosci Res 2002, 44:405-419.

83. Mesulam MM: Tetramethylbenzidine for horseradish peroxidase neurohistochemistry: A non-carcinogenic blue reaction product with superior sensitivity for visualizing neural afferents and efferents. J Histochem Cytochem 1978, 26:106-II7.

84. Llewellyn-Smith IJ, Pilowsky P, Minson JB: The tungstate-stabilized tetramethylbenzidine reaction for light and electron microscopic immunocytochemistry and for revealing biocytinfilled neurons. J Neurosci Meth 1993, 46:27-40.

Publish with Bio Med Central and every scientist can read your work free of charge

"BioMed Central will be the most significant development for disseminating the results of biomedical research in our lifetime. "

Sir Paul Nurse, Cancer Research UK

Your research papers will be:

- available free of charge to the entire biomedical community

- peer reviewed and published immediately upon acceptance

- cited in PubMed and archived on PubMed Central

- yours - you keep the copyright

Submit your manuscript here:

http://www.biomedcentral.com/info/publishing_adv.asp
BioMedcentral 